\title{
Maternal transfer of chlorinated contaminants in the leatherback turtles, Dermochelys coriacea, nesting in French Guiana
}

\author{
Elodie Guirlet ${ }^{\mathrm{a}, \mathrm{b}, \mathrm{c}, *}$, Krishna Das $^{\mathrm{c}}$, Jean-Pierre Thoméd ${ }^{\mathrm{d}}$, Marc Girondot ${ }^{\mathrm{a}, \mathrm{b}}$ \\ a Laboratoire Écologie, Systématique et Évolution (UMR8079), Université Paris-Sud, Bâtiment 362, 91405 Orsay, France \\ ${ }^{\mathrm{b}}$ AgroParisTech, CNRS, 91405 Orsay, France \\ ${ }^{\mathrm{C}}$ Laboratoire d'Océanologie, Centre de Recherche MARE, Université de Liège, B6 C, B-4000 Liège, Belgique \\ ${ }^{\mathrm{d}}$ Laboratoire d'Ecologie Animale et Ecotoxicologie, Université de Liège, B6 C, B-4000 Liège, Belgique
}

\section{A R T I C L E I N F O}

\section{Article history:}

Received 22 October 2009

Received in revised form 17 February 2010

Accepted 21 February 2010

\section{Keywords:}

Marine turtles

PCBs

OCPs

Eggs

Blood

Spatial and temporal variation

\begin{abstract}
A B S T R A C T
We examined the maternal transfer of organochlorine contaminants (OCs), pesticides (DDTS and HCHs) and polychlorinated biphenyls (PCBs), and the temporal variation of blood and eggs concentrations from 38 leatherback turtles (Dermochelys coriacea) nesting in French Guiana. PCBs were found to be the dominant OCs with respective mean concentrations of $55.14 \mathrm{ng} \mathrm{g}^{-1}$ lipid-mass for egg and $1.26 \mathrm{ng} \mathrm{mL}^{-1}$ wetmass for blood. OC concentrations were lower than concentrations measured in other marine turtles which might be due to the lower trophic position (diet based on gelatinous zooplankton) and to the location of their foraging and nesting grounds. All OCs detected in leatherback blood were detected in eggs, suggesting a maternal transfer of OCs. This transfer was shown to depend on female blood concentration for $\Sigma$ DDTs and for the most prevalent PCB congeners, since significant relationships were found between paired blood-egg concentrations. During the nesting season, OC concentrations in eggs and the percentage of lipid in eggs were found to decline in successive clutches, highlighting a process of offloading from females to their eggs and a decreasing investment of lipid from females into their clutches. OCs in eggs tended to be higher in females spending 3 years in the foraging grounds between two nesting seasons than in those spending 2 years, suggesting an impact of time spacing two breeding seasons, called remigration interval, and of location of the foraging grounds.
\end{abstract}

(C) 2010 Elsevier Ltd. All rights reserved.

\section{Introduction}

Pollution and pollution-related disease have been cited as presenting increasingly greater threats to populations of reptiles (Gibbons et al., 2000). Environmental contaminants such as organochlorine compounds (OCs) including polychlorinated biphenyls (PCBs) and organochlorine pesticides (OCPs) have been widely detected in environmental samples, since they have been extensively used in anthropogenic activities (Snedaker et al., 1999). Since the restriction of the use of persistent organic pollutants, levels in the environment are now expected to decrease (Aguilar and Borrell, 2005). However, large quantities of chemicals are still used in agriculture and vector control in tropical countries (Lacher and Goldstein, 1997). Exposure to OCs is known to affect immune, reproductive and endocrine function in reptiles leading to deleterious effects such as disruption of sex determination, decreased hatching rate and increased hatchling deformities and disorienta-

\footnotetext{
* Corresponding author. Address: Laboratoire d'Océanologie, Centre de Recherche MARE, Université de Liège, B6 C, B-4000 Liège, Belgique. Tel.: +32 4366 3328; fax: +3243665147.

E-mail address: e.guirlet@gmail.com (E. Guirlet).
}

tion (Bishop et al., 1991, 1998; Bergeron et al., 1994). But the exact role of chemical pollutants in sea turtle health is not known and no information on toxicological effects and detrimental threshold is available for marine reptiles.

The leatherback turtle, Dermochelys coriacea, is the most pelagic marine turtle and migrates over thousands of kilometers between foraging and nesting grounds to feed upon gelatinous zooplankton (Davenport, 1998; Hays et al., 2004). Contaminant exposure of marine turtles may vary according to the level of contamination and time spent on foraging grounds (Keller et al., 2004b). Indeed turtles may forage for several years between two reproduction periods and this feeding interval is defined as the remigration interval (RI, Rivalan et al., 2005). While some turtles may feed repeatedly in contaminated sites others may feed in more pristine areas. We showed previously that leatherback turtles nesting on Yalimapo beach in French Guiana, a major nesting site for the species, displayed a low hatching rate (Caut et al., 2006) and detectable but low levels of toxic trace elements in blood and eggs (Guirlet et al., 2008). This raises concerns about other environmental contaminants such as OCs which have been shown to affect sensitive early stages of life and the viability of the offspring of several reptiles 
species; these adverse effects have been shown for eggs treated experimentally with low dose of pesticides (between 0.25 and $14 \mathrm{ng}$ of trans-Nonachlor, chlordane or $p p^{\prime}$-DDE per egg) or for eggs sampled in contaminated areas with concentrations up to 1000 and $3500 \mathrm{ng} \mathrm{g}^{-1}$ of pesticides and PCBs respectively (Woodward et al., 1993; Bishop et al., 1998; Willingham, 2001). Current levels have been described in marine turtles (Supporting Material - SM, Table 1), however toxicokinetic and potentially harmful effects of OCs remain poorly known. Investigations into these types of contaminants could help to assess the potential risk to turtle's health. To assess a baseline of OC concentrations in free-ranging leatherback, non-lethal and adequate sampling is required in the form of blood and egg samples that can be easily collected. Blood is relatively non-invasive and facilitates the repeated collection of larger numbers of samples which improves both monitoring of OC levels and assessment of toxicological effects. As egg formation occurs when females forage in pelagic waters about 4-5 months before arriving at nesting sites (James et al., 2005a) and as it is thought that leatherback females from French Guiana are not eating or eat only a little during the nesting season (Fossette et al., 2007; Caut et al., 2008), contaminants in the female's blood and eggs are likely to represent their lipid stores which represent the contamination they accumulated on their foraging ground. Moreover, concentrations in eggs reflect the exposure of the developing embryo, a stage during which toxic effects may be more detrimental than during adulthood.

While diseases are increasing in marine ecosystems (Ward and Lafferty, 2004), ecotoxicological data remains scarce in marine turtles. Among them, leatherbacks have the biggest reproductive output in reptiles and migrate over thousands of kilometer during migrations facilitating exposure to various environmental toxicants (Miller, 1997) making this species particularly interesting to study in terms of maternal transfer of contaminants. In this study, we assessed this maternal transfer of OCs, described the distribution, patterns and relationships of PCBs and OCPs in blood and egg sampled in 38 nesting leatherbacks. We also investigated the temporal variations of this transfer along and between nesting seasons.

\section{Materials and methods}

\subsection{Study site and sample collection}

The study was conducted at Yalimapo beach situated within the Amana Natural Reserve in French Guiana. Leatherback females are marked with an internal permanent marker (Passive Integrated Transponder [PIT] tag) located in the shoulder muscle. These coded microchips are used to identify leatherback turtles and to allow temporal monitoring for females during and between nesting seasons. From this information, we were able to know how many nests had occurred between two nesting observations and since how many years this female has nested previously (mainly of 2 or 3 years). From 16th March to 14th May 2006, we patrolled the beach each night around high tide. Nesting females encountered during patrols were scanned for PIT tags and blood and eggs were sampled during egg-laying. We also sampled adipose tissues in the shoulder but biopsies revealed that there were no more adipose reserves here at the beginning of the nesting season. One yolked-egg was collected arbitrarily around the 20th egg laid and whole blood was sampled from the rear flipper and samples were then frozen at $-20^{\circ} \mathrm{C}$ until analysis. For this study 38 females were sampled including 17 females for two different clutches and three females for three different clutches either consecutive or not.

\subsection{Sample preparation}

Egg content (yolk and albumen) were homogenized with an Ultra-Turax. A $4 \mathrm{~g}$ sample was lyophilized for $16 \mathrm{~h}$ and dry matter was determined gravimetrically. To $500 \mathrm{mg}$ sample of lyophilized egg were added $500 \mathrm{mg}$ of anhydrous sodium sulfate and $50 \mu \mathrm{L}$ of PCB 112 (100 pg $\mu \mathrm{L}^{-1}$ in acetone) used as surrogate marker. These spiked samples with surrogate were extracted with a mixture of hexane, dichloromethane and methanol (5:2:1, v:v:v) at $80^{\circ} \mathrm{C}$ under a pressure of $1500 \Psi$ using an accelerated solvent extractor (Dionex ASE 2000). The solvent with extracted fat were collected in pre-weighed vials and evaporated at $40{ }^{\circ} \mathrm{C}$ under a gentle nitrogen flow (Turbovap) and fat content was determined gravimetrically. The residues containing both lipids and OCs of interest were dissolved into $3 \mathrm{~mL}$ of hexane and collected into a test tube. The mixture was homogenized by vortexing for $1 \mathrm{~min}$. Blood samples were prepared by a method modified from Pauwels et al. (1999), Janak et al. (1999) and Sunbdberg et al. (2006). Four millilitres of blood were first deproteinised by adding $100 \mu \mathrm{L}$ of triethylamine and $5 \mathrm{~mL}$ of formic acid; $50 \mu \mathrm{L}$ of PCB $112\left(100 \mathrm{pg} \mu \mathrm{L}^{-1}\right.$ in acetone) were used as surrogate marker. The mixture was stabilized for $30 \mathrm{~min}$ in an ultrasound bath. Five millilitres of hexane were added and samples were shaken manually for 2 min and centrifuged for $10 \mathrm{~min}$ at $3000 \mathrm{rpm}$. The organic phase was transferred into a new tube and evaporated under a gentle stream of nitrogen in order to obtain a final volume of $1 \mathrm{~mL}$.

\subsection{Sample clean-up and analysis}

All prepared samples (egg and blood) were purified by acid and Florisil clean-ups. Sample clean-up were performed as detailed in Debier et al. (2003). The egg and blood purified extracts were analysed by high resolution gas chromatography using a Thermo Quest Trace 2000 gas chromatograph equipped with a $\mathrm{Ni}^{63} \mathrm{ECD}$ detector and an autosampler for liquids Thermo Quest AS 2000. Analysis of samples is also describes in Debier et al. (2003). Twenty-three PCB pure components (IUPAC 28, 44, 52, 66, 70, 87, $95,101,105,118,128,138,149,153,156,170,180,183,187$, $194,195,206,209)$ and 5 OCPs of interest ( $p p^{\prime}$-DDT, $p p^{\prime}$-DDE, $p p^{\prime}$-DDD, $\alpha-\mathrm{HCH}$ and $\gamma-\mathrm{HCH}$ ) were measured.

\subsection{Quality assurance}

The quality control was performed by analyses of procedural blanks, by injection of standard and $n$-hexane blanks. Standard reference materials SRM 1946 (PCBs and OCPs in Lake Superior fish tissue) and BCR RM 349 (cod liver), were used to test the whole procedure of the analytical method accuracy (recovery efficiency for certified concentrations between $71 \%$ and $128 \%$ according to the compounds). Procedural blanks and laboratory made quality control were run with each set of samples to control the extraction and clean-up procedures. Blanks were also used to control lyophilization and ASE steps for egg samples. The laboratory made quality controls $(\mathrm{QC})$ were bovine blood and milk cream, for blood and egg series respectively, spiked with a PCBs and OCPs mix at 2.5 and $15 \mathrm{ng} \mathrm{g}^{-1}$ for bovine blood and milk cream respectively. For each PCB congener and OCP, recovery efficiency was calculated on the basis of the concentration of the surrogate marker PCB 112. All results were corrected to obtain $100 \%$ recovery. However, the results of the PCBs and OCPs analyses were accepted only if the recoveries were between $70 \%$ and $130 \%$. In egg samples, concentrations were calculated on a wet-mass basis and on a lipid-mass basis in order to minimize inter-individual variation and to allow comparison of results with other studies. For blood samples, concentrations are only expressed on a wet-mass basis as the lipid fraction in blood is known to be very low ( $<1 \%$, Keller et al., 2004c). Total PCBs 
concentrations ( $\Sigma \mathrm{PCBs}$ ) were calculated as the sum of all individual quantified congeners, total DDTs ( $\Sigma$ DDTs) as the sum of $p p^{\prime}-$ DDT, $p p^{\prime}$-DDE and $p p^{\prime}$-DDD concentrations and total HCHs ( $\Sigma$ HCHs) as the sum of $\alpha-\mathrm{HCH}$ and $\gamma-\mathrm{HCH}$ concentrations. For each PCB congeners and OCPs, the limits of quantification (LOQ) were $0.09 \mathrm{ng} \mathrm{g}^{-1}$ and $0.08 \mathrm{ng} \mathrm{g}^{-1}$ for egg and blood samples respectively. The efficiency recovery for PCB congeners and of OCPs was always above $75 \%$ for egg and blood samples.

\subsection{Statistical analysis}

For statistical analysis, OC concentrations that were below the limit of quantification (LOQ) were estimated at half the LOQ. Firstly, general linear models (GLM) with repeated measurements were carried out to investigate the variations in concentration of

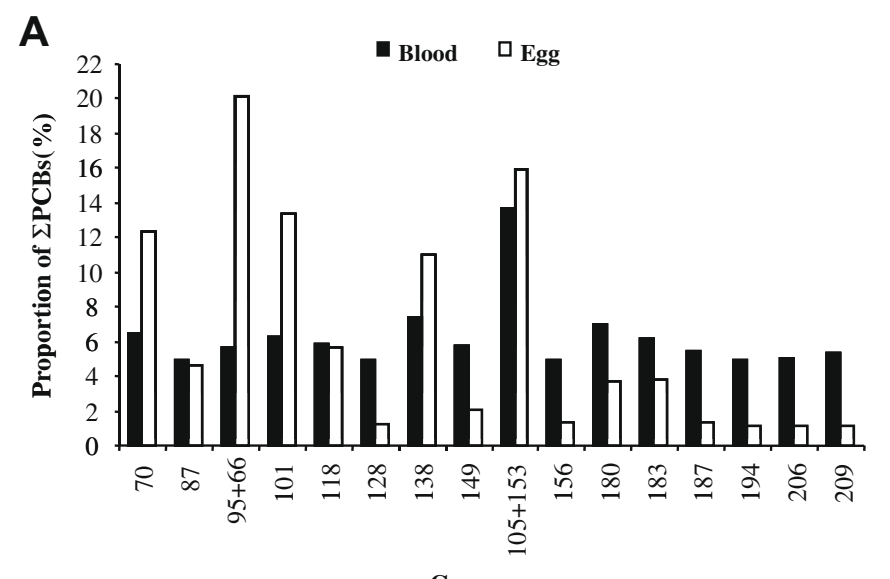

B

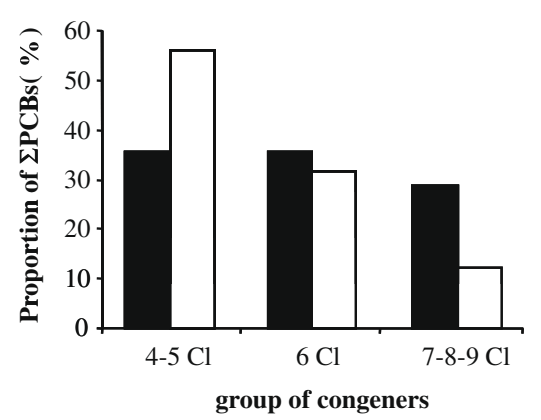

Fig. 1. $\mathrm{PCB}$ patterns (percentage of $\Sigma \mathrm{PCBs}$ ) in leatherback blood and egg samples (wet-mass basis): (A) for each congener (B) by group of congeners (according to chlorination of congeners).
OCs and lipid percentage during the nesting season; the dependent variable was the sum of concentrations for a class of OCs or the percentage of egg lipid content, and the independent variable was the nest laying interval between clutches, in days, (the time 0 corresponded to the day when we observed the first clutch for each female). For both egg and blood concentrations, repeated measurements were used to compare data from the same female at different nesting events. Differences in OC concentrations and proportions between 2-year and 3-year RI females were then investigated. General linear mixed models (GLMM) for each tissue (egg and blood) and each sum of class of OCs (the dependent variables of each model) were carried out. We used mixed models because values for the same female at different times (representing different laying events) were correlated; this covariance structure was handled by introducing the individual females as a random effect into the GLMM. GLM with binomial error distribution and logit link function were also performed to assess the effect of RI on the proportion of each class of contaminant analyzed. Finally, GLMM were performed to test the relationship between concentrations in eggs when regressed against corresponding concentrations in blood. Simple regression models were then applied to look at potential correlations between concentrations of OCs in eggs and in blood. The normality of the dependent variables was confirmed prior to the analyses. Computations were performed with the SAS package.

\section{Results}

\subsection{Concentrations and patterns}

Due to interference during analysis, PCBs 28, 44, 52, 170 and 195 could not have been properly detected and quantified and they were therefore removed from samples profiles. For each congener, the mean percentage contribution to $\Sigma$ PCBs, called congener pattern, was calculated. Congener pattern is dominated in blood by the more chlorinated congeners whereas congener patterns in eggs were dominated by the less chlorinated congeners (Fig. 1A). When grouping congeners by degree of chlorination (4-5 Cl, $6 \mathrm{Cl}$ and 7-9 $\mathrm{Cl}$, each class having approximately the same number of congeners), the three groups were equally represented in blood (Fig. 1B) but the group's patterns present a tendency for the lower chlorinated group in eggs (Fig. 1B). In blood, PCBs were the predominant OCs found. PCBs 153, which is generally the most persistent and abundant congeners found in biological tissues, is the most prevalent congener detected in blood (56.3\% of occurrence). DDT and metabolites were the second class followed by HCHs compounds (Table 1). $p p^{\prime}$-DDE was detected in $58.3 \%$ samples contrasting with $p p^{\prime}$-DDT and $p p^{\prime}$-DDD which occurred only in $2.1 \%$ and $6.3 \%$, respectively. In eggs, PCBs were the predominant OCs class found

Table 1

Organochlorine contaminant concentrations in leatherback blood and egg samples from French Guiana and egg lipid content.

\begin{tabular}{|c|c|c|c|c|c|}
\hline & & $\Sigma$ PCBs & ¿DDTs & $\Sigma \mathrm{HCHs}$ & \% Lipids \\
\hline Blood (ng mL ${ }^{-1}$ ) & $\begin{array}{l}\text { Mean } \pm \text { SD } \\
\text { Range } \\
n \\
\% \text { of } \Sigma O C s\end{array}$ & $\begin{array}{l}1.26 \pm 0.71 \\
0.86-4.04 \\
43 \\
72.9\end{array}$ & $\begin{array}{l}0.31 \pm 0.22 \\
0.09-1.04 \\
44 \\
18.1\end{array}$ & $\begin{array}{l}0.15 \pm 0.16 \\
0.09-0.90 \\
14 \\
9\end{array}$ & \\
\hline Egg (ng g ${ }^{-1}$ wet mass) & $\begin{array}{l}\text { Mean } \pm \text { SD } \\
\text { Range } \\
n \\
\% \text { of } \Sigma O C s\end{array}$ & $\begin{array}{l}6.98 \pm 5.02 \\
1.18-23.62 \\
46 \\
79\end{array}$ & $\begin{array}{l}1.44 \pm 1.26 \\
0.08-5.82 \\
43 \\
16.3\end{array}$ & $\begin{array}{l}0.41 \pm 0.26 \\
0.08-1.06 \\
44 \\
4.7\end{array}$ & $\begin{array}{l}12.9 \pm 5.1 \\
3.8-25.5 \\
50\end{array}$ \\
\hline Egg (ng g ${ }^{-1}$ lipid) & $\begin{array}{l}\text { Mean } \pm \text { SD } \\
\text { Range } \\
n \\
\% \text { of } \Sigma O C s\end{array}$ & $\begin{array}{l}55.14 \pm 43.17 \\
4.40-189.87 \\
46 \\
79.2\end{array}$ & $\begin{array}{l}11.03 \pm 9.04 \\
0.12-37.35 \\
43 \\
15.9\end{array}$ & $\begin{array}{l}3.43 \pm 2.13 \\
0.08-9.87 \\
44 \\
4.9\end{array}$ & \\
\hline
\end{tabular}


(Table 1). PCBs $153+105$ are detected in all egg samples (the proportion of congener 105 being estimated to $10 \%$ of the peak $153+105)$. $\Sigma$ DDTs were the second most abundant OCs class measured, represented mainly by the major metabolite $p p^{\prime}$-DDE which occurred in $86 \%$ samples contrasting with $p p^{\prime}$-DDT and $p p^{\prime}$-DDD which occurred only in $4.4 \%$ and $6.7 \%$ of samples respectively.

\subsection{Fluctuations during the nesting season}

Concentrations in blood remained constant during the nesting season $(P=0.209$ and $P=0.610$ for $\Sigma$ PCBs and $\Sigma$ DDTs respectively) except for $\Sigma \mathrm{HCHs}$ for which concentrations slightly increased $(P=0.010)(\mathrm{SM}$, Fig. 1). In contrast, concentrations in eggs on a wet-mass basis decreased significantly during the nesting season from one clutch to the next $(P=0.003, P=0.003, P=0.001$ for $\Sigma$ PCBs, $\Sigma$ DDTs and $\Sigma$ HCHs respectively). The mean percentage of lipid was $12.9 \%$ of the egg content $(S D=5.1 \%$, range $3.8-25.5 \%$ ) but a significant decrease in the percentage of lipid was observed for eggs collected later in the nesting season $(P=0.005)(\mathrm{SM}$, Fig. 1). After lipid normalization, concentrations in eggs still decreased $(P=0.042$ and $P=0.007$ for $\Sigma P C B$ and $\Sigma D D T$ respectively) but become constant for $\Sigma$ HCHs $(P=0.192)$ (SM, Fig. 1).

\subsection{Variation in concentrations with remigration interval}

No significant difference was observed between the blood concentrations of the 2 and 3 years remigrant females for $\Sigma P C B$ and $\Sigma \mathrm{HCHs}(P=0.104$ and $P=0.899$ respectively). Concerning $\Sigma$ DDTs, a significant difference was observed $(P=0.017)$ with the 3 years remigrant females having higher $\Sigma$ DDTs blood concentrations than

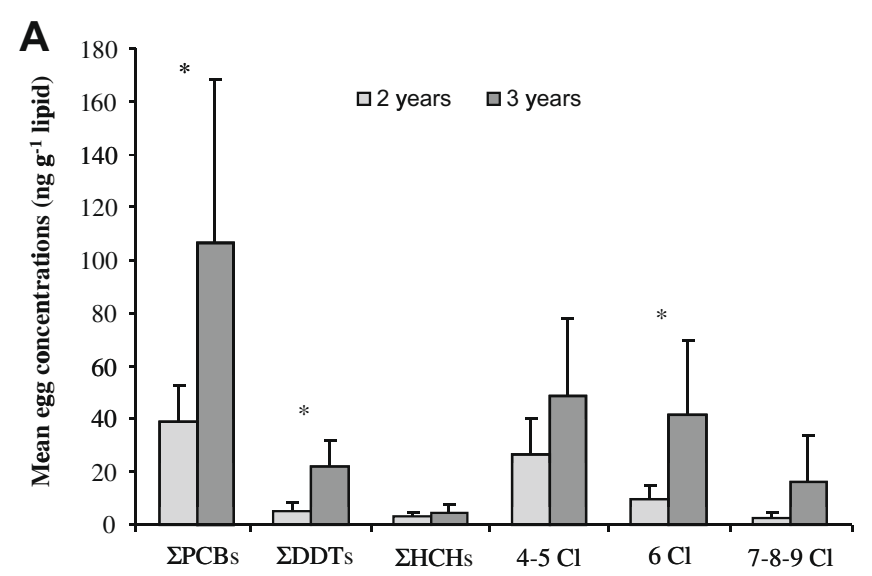

\section{B}

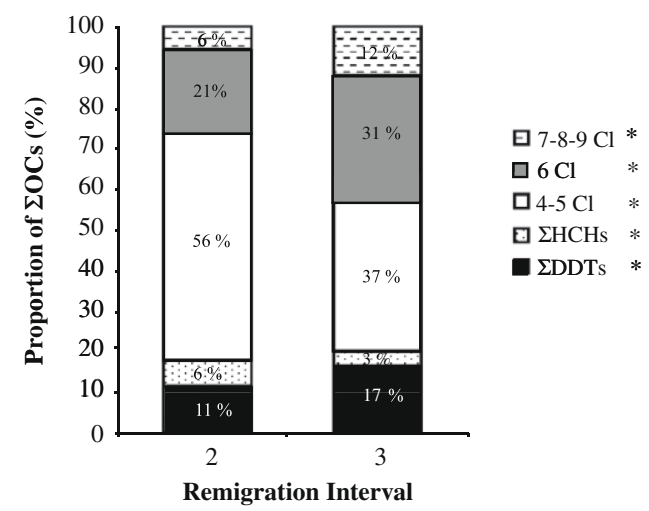

Fig. 2. Effect of remigration interval on the $O C$ concentrations (A) and on the proportions of each OC class (B) in leatherback eggs from French Guiana. Significant statistical differences are marked with $*$.
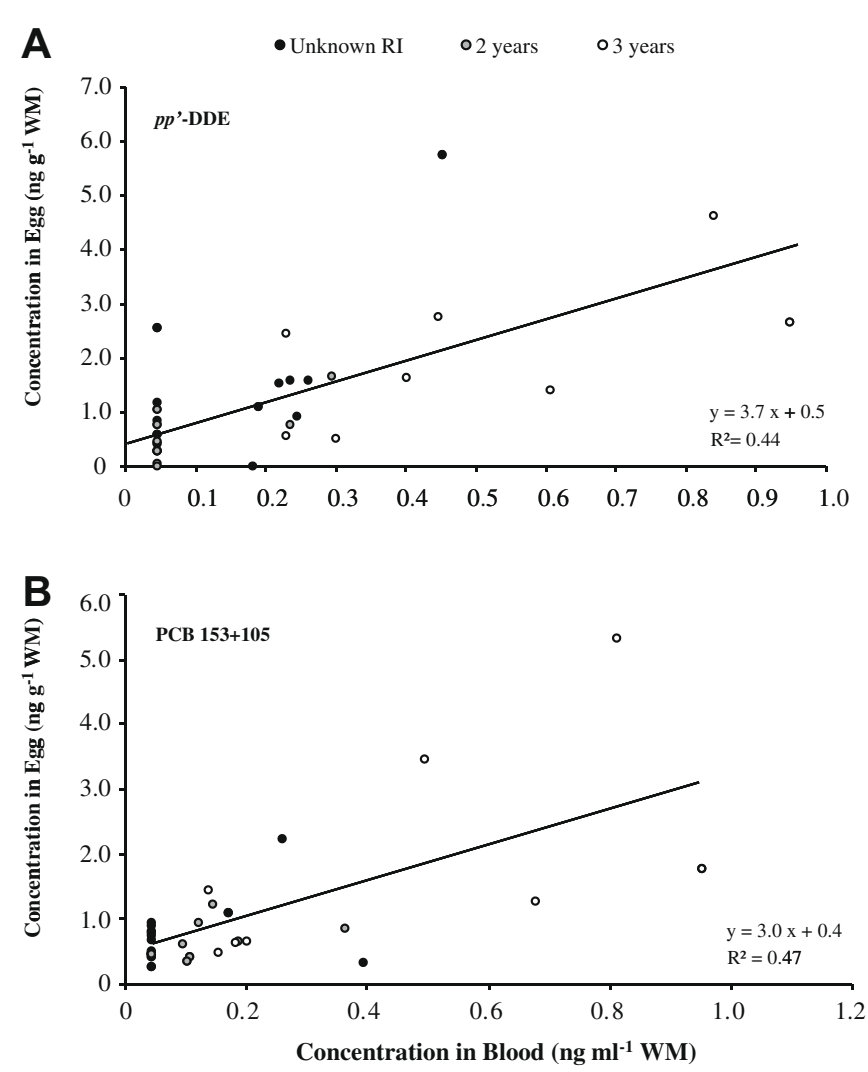

Fig. 3. Relationship between $O C$ concentrations in eggs and in blood (wet-mass basis) in leatherback turtles sampled in French Guiana for $p p^{\prime}-\mathrm{DDE}(\mathrm{A})$ and PCB $153+105$ (B)

the 2 years females. Concerning eggs, the RI had a significant effect on $\Sigma$ PCBs and $\Sigma$ DDTs $(P=0.017$ and $P=0.001$ respectively $)$ but not for $\Sigma$ HCHs $(P=0.173)$ (Fig. $2 \mathrm{~A})$. When using chlorination groups as dependent variables, higher chlorinated groups of congeners presented higher concentrations in the 3 years remigrant females with a significant difference for the $6 \mathrm{Cl}$ group $(P=0.016)$ (Fig. 2A). Finally, when comparing the proportion of $\Sigma$ OCs according to the RI, it appears that the 3 years remigrant females present a higher proportion of high chlorinated groups of congeners $(6 \mathrm{Cl}$ group: $P<0.001$ and $7-9 \mathrm{Cl}$ group: $P<0.001)$ and a significant lower proportion of low chlorinated group of congeners (4-5 $\mathrm{Cl}$ group: $P<0.001$ ) compared to the 2 years remigrant females (Fig. $2 \mathrm{~B}$ ).

\subsection{Relationship between egg and blood concentrations}

Significant relationships were found for $\Sigma$ DDTs and $p p^{\prime}$-DDE $(P=0.0009$ and $P=0.0001$ respectively) for which concentrations in eggs were positively correlated with their corresponding concentrations in blood (wet-mass basis). For $\Sigma$ PCBs and $\Sigma$ HCHs, relationship were not significant $(P=0.1602$ and $P=0.0626$, respectively). When taking the most prevalent congeners alone (congeners $153+105,180$ and 138 ) to display the correlation, the relationships were highly significant $(P=0.0060, P=0.0034$ and $P=0.0001$, respectively). Simple linear regressions for $p p^{\prime}$-DDE and PCB $153+$ 105 in eggs compared with concentrations in blood are presented in Fig. 3 and confirmed the statistically significant relationship.

\section{Discussion}

Leatherbacks in this study present low OC concentrations in blood and eggs probably resulting from their low trophic level with a diet based mainly on jellyfish (Davenport, 1998). These low levels 
may also result from the pollution status of the region where turtles are living: nesting grounds in French Guiana and oceanic foraging grounds mainly used by leatherbacks, remote from coastal anthropogenic sources (James et al., 2005b; Doyle et al., 2007). OC concentrations in leatherback eggs are close to those observed in the herbivorous green turtle and lower than those encountered in omnivorous loggerhead turtles (SM, Table 1). In oviparous organisms, early stages of life often exhibit a greater sensitivity to contaminants (Russell et al., 1999). But concentrations of OCs in eggs of this study remain very low and below concentrations that have been described for deleterious effects: decreased viability in clutches of alligators for egg treated with OCPs (11 $075 \mathrm{ng} \mathrm{g}^{-1}$ yolk for DDE, Rauschenberger et al., 2004); altered reproduction in sea birds with adverse effects established for $2300 \mathrm{ng} \mathrm{g}^{-1}$ wet mass for $\Sigma$ PCBs in egg (Fisk et al., 2005); and increased developmental abnormalities in embryos and hatchlings in aquatic turtles eggs from contaminated lakes (3575 $\mathrm{ng} \mathrm{g}^{-1}$ and $389 \mathrm{ng} \mathrm{g}^{-1}$ wet mass for $\Sigma$ PCBs and DDE respectively from Lake Ontario, Bishop et al., 1998). Further investigations would be however needed to assess toxic thresholds at which adverse effects occur in marine turtle eggs. OCs may also impact marine reptiles at later stages. Correlations between clinical health parameters and OCs in juvenile loggerhead sea turtles have indeed suggested that sea turtles may be relatively sensitive to sub lethal effects of OCs, like modulation of the immune system or alteration of protein, ion and carbohydrate homeostasis. This negative effect could occur even at much lower concentrations than those in studies listed above (blood concentration for $\Sigma$ PCBs and DDE respectively $5.56 \mathrm{ng} \mathrm{g}^{-1}$ and $0.65 \mathrm{ng} \mathrm{g}^{-1}$ wet mass (Keller et al., 2004a), concentrations close to those encountered in leatherbacks from our study). Ward and Lafferty (2004) reported indeed an increasing trend in disease occurrence in marine turtles and environmental pollutants are expected to be partly responsible for these infectious diseases but their exact effect on sea turtle health is little known and need therefore further studies.

OC concentrations are expected to vary in blood during periods of high energy requirements because of a release of OCs stored in adipose tissue into the bloodstream after lipid mobilization. OC fluctuations have been effectively shown in blood of turtles and seals after periods of high mobilization of stores during fasting or low food intake (Lydersen et al., 2002; Keller et al., 2004b; Debier et al., 2006). In the leatherback females, lipid mobilization is also likely to occur during migration or vitellogenesis. The nesting season could also be a phase of high energy requirement because of the numerous massive clutches to lay (Girondot and Fretey, 1996) and because females may go through this period with little or no food intake (Fossette et al., 2007; Caut et al., 2008). Blood concentrations for $\Sigma$ PCBs and $\Sigma$ DDTs remain constant suggesting no increase of release of this class of OCs from lipid reserves into the bloodstream during the nesting season. A hypothesis is that lipid reserves have already been mobilized during migration or egg production, periods during which the costs are larger than those during the nesting season (Wallace et al., 2005). The fact that sea turtles display an important weight loss between foraging grounds and nesting sites (depletion of $33 \%$ of body mass, James et al., $2005 \mathrm{~b}$ ) and the fact that no adipose tissue were found in the flipper of these females at the beginning of nesting season support this hypothesis.

In oviparous species, females often transfer a part of their burden to their eggs due to the lipophilic nature of OCs (Rauschenberger et al., 2002). Indeed, all of the substances detected in leatherback blood were also detected in eggs confirming that maternal transfer. The absence of parallelism between congener patterns in females and their progeny have already been described in marine vertebrates (turtles, birds, mammals; McKenzie et al., 1997, 1999; Miao et al., 2001; Verreault et al., 2006). This suggests a preferential reproductive transfer of lower chlorinated groups from blood to eggs based on the lipophilic nature of the compound being transferred, the more chlorinated and lipophilic compounds being the more difficult to transfer. In our study, maternal transfer for $\Sigma$ DDTs and the most prevalent PCB congeners was depending on concentrations in female blood (the lack of correlation for $\Sigma$ PCBs is certainly due to the very low occurrence of the majority of congeners in blood samples); eggs concentrate pollutants proportionally to those accumulated by female. In turtles, lipids and proteins in egg-yolk are the primary reserves that will provide energy and building materials to facilitate embryogenesis (Wallace et al., 2006). Eggs are provided with those nutrients and energy during vitellogenesis during which lipophilic OCs are also mobilized and transferred into the developing ova (Wu et al., 2000). Intra-clutch variation is not likely to occur in turtles, since the supply of yolk is simultaneous and equal in follicles forming one clutch (Bowden et al., 2004). But in contrast inter-clutch variation could occur as vitellogenesis of all clutches to be laid does not necessarily happen at the same time. A decreasing trend occurred in OCs concentrations in clutches throughout the nesting season. This could suggest a progressive offloading of the female through its clutches: the first clutch being the most contaminated as the female burden is higher at the beginning of the nesting season. Then the female burden decreases with each clutch produced. A similar decline has been documented in birds that exhibit sequential ovulation for a clutch leading to a decreasing trend in OCs concentrations in eggs of a clutch in relation to laying order (Van den Steen et al., 2009). Our results show also a significant decrease in egg-lipid percentage between clutches suggesting that yolk deposition in follicles is not equal for all clutches to be laid and that the reproductive investment from females into their subsequent clutches decreases. These results are in contrast with other results on green turtles in which the lipid concentrations are constant throughout the nesting season (Hamann et al., 2002). This difference may be due to the particularity of leatherback to have lipid reserves already largely depleted at their arrival on nesting site. Indeed, adipose tissue could not have been sampled in that study probably resulting from the large depletion of body mass (James et al., 2005b). In sea turtles, once vitellogenesis is initiated follicles grow continuously prior to the nesting season (Miller, 1997) but if female lipid reserves decrease, lipid yolk deposition would decrease too: the follicles provisioned with lipids while female fat reserves decrease are likely to have decreased lipid content.

In our study, eggs from females that spent 3 years on the foraging grounds present higher $\mathrm{OC}$ concentrations in their eggs and higher proportions of high chlorinated congeners than do the 2 years remigrant females. This difference may be linked first to the length of the RI. Leatherbacks are indeed capital breeders generally spacing out consecutive breeding seasons every 2 or 3 years (Rivalan et al., 2005). Females spending more years on foraging grounds may have higher contaminant burden resulting from a longer trophic contamination and they may therefore transfer more contaminants to their eggs. But the concentrations encountered in the 3 years remigrant females, almost twice as those of the 2 years remigrant females, cannot simply be explained by an additional year of trophic contamination. The difference in egg concentrations and patterns between remigrant females may also be linked to the location of the foraging grounds. Feeding locations have already been shown to be responsible for the inter-individual difference in $O C$ concentrations among females and to influence the levels and patterns of OCs transferred to eggs (Alava et al., 2006). Turtles foraging in offshore areas have been shown to be less exposed than turtles foraging closer to the coast (Day, 2003) and the distributions of PCBs found in the open sea are known to be oriented towards less chlorinated congeners which are relatively more volatile than highly chlorinated congeners found in 
continental shelf waters (Dachs et al., 1997). As congeners patterns in eggs of the 2 years remigrant females is oriented toward lower chlorinated congeners, therefore more volatile congeners, and that their OCs concentrations are lower than the 3 years remigrant females, the 2 years remigrant females are thought to forage in more oceanic area compared to the 3 years remigrant females. Foraging areas for leatherbacks are located all around the North Atlantic Ocean (Houghton et al., 2006; Doyle et al., 2007) in both offshore and more costal areas likely to differ in levels of contamination due to anthropogenic activity in coastal zones. The different concentrations between remigrant females may finally be the result of complex interaction between length of the RI and location of foraging grounds. In a previous study, leatherback females have indeed been shown to present different isotopic signatures according to their RI suggesting that remigrant females use different foraging grounds. Isotope signatures could provide information on both the latitude, and the pelagic vs. neritic nature of the foraging ground (Kelly, 2000; Takai et al., 2000) and it has been possible to reveal that the 2 years remigrant females seem to feed in a more northern and/or offshore area and the 3 years remigrant females in a more southern and/or coastal areas (Caut et al., 2008).

\section{Conclusion}

This study provides the first ecotoxicological data for OCs in living leatherbacks. The results show important differences in term of contamination level between females according to their RI. This highlights the importance of the time spent on foraging grounds and the level of contamination and location of these foraging grounds. The level of contamination remains however low in all females' samples but despite these low concentrations, a maternal transfer of OCs occurs and eggs are contaminated. In oviparous organisms, early stages of life often exhibit a greater sensitivity to contaminants but despite the fact that level of hatching success on Yalimapo beach has been shown to be low, the causal link between OC and embryonic mortality is unlikely on this site.

\section{Acknowledgements}

We thank DIREN-Guyane for the use of the facilities of the Amana Nature Reserve. Samples were obtained during a joint field mission with the CEPE-CNRS UPR 9010, 67087 Strasbourg and we thank all those who helped in the field work: X. Desparde (ESE, Paris), J.Y. Georges and S. Fossette (CEPE, Strasbourg). The field work was conducted under legal permit from the French government, via a collaborative agreement with the group of Dr. J.Y. Georges. The subsequent transport of the field samples was authorized by a permit from the French government (Préfecture de la Guyane) granted in 2006. The authors are grateful to M. Louvet for valuable technical assistance in organochlorine analysis. $\mathrm{K}$. Das is supported by FRS-FNRS. This is a MARE publication 186.

\section{Appendix A. Supplementary material}

Supplementary data associated with this article can be found, in the online version, at doi:10.1016/j.chemosphere.2010.02.047.

\section{References}

Aguilar, A., Borrell, A, 2005. DDT and PCB reduction in the western Mediterranean from 1987 to 2002, as shown by levels in striped dolphins (Stenella coeruleoalba). Mar. Environ. Res. 59, 391-404.

Alava, J.J., Keller, J.M., Kucklick, J.R., Wyneken, J., Crowder, L., Scott, G.I., 2006. Loggerhead sea turtle (Caretta caretta) egg yolk concentrations of persisten organic pollutants and lipid increase during the last stage of embryonic development. Sci. Total Environ. 367, 170-181.
Bergeron, J.M., Crews, D., McLachlan, J.A., 1994. PCBs as environmental estrogens: turtle sex determination as a biomarker of environmental contamination. Environ. Health Perspect. 102, 780-781.

Bishop, C.A., Brooks, R.J., Carey, J.H., Ng, P., Norstrom, R.J., Lean, D.R.S., 1991. The case for a cause-effect linkage between environmental contamination and development in eggs of the common snapping turtle (Chelydra s. serpentina) from Ontario, Canada. J. Toxicol. Environ. Health 33, 521-547.

Bishop, C.A., Ng, P., Pettit, K.E., Kennedy, S.W., Stegeman, J.J., Norstrom, R.J., Brooks, R.J., 1998. Environmental contamination and developmental abnormalities in eggs and hatchlings of the common snapping turtle (Chelydra serpentina serpentina) from the Great Lakes St Lawrence River basin (1989-91). Environ. Pollut. 101, 143-156.

Bowden, R.M., Harms, H.K., Paitz, R.T., Janzen, F.J., 2004. Does optimal egg size vary with demographic stage because of a physiological constraint? Funct. Ecol. 18, 522-529.

Caut, S., Guirlet, E., Jouquet, P., Girondot, M., 2006. Influence of nest location and yolkless eggs on the hatching success of leatherback turtle clutches in French Guiana. Can. J. Zool. - Rev. Can. Zool. 84, 908-915.

Caut, S., Guirlet, E., Angulo, E., Das, K., Girondot, M., 2008. Isotope analysis reveals foraging area dichotomy for atlantic leatherback turtles. PLoS One 3, e1845

Dachs, J., Bayona, J.M., Albaiges, J., 1997. Spatial distribution, vertical profiles and budget of organochlorine compounds in Western Mediterranean seawater. Mar. Chem. 57, 313-324.

Davenport, J., 1998. Sustaining endothermy on a diet of cold jelly: energetics of the leatherback turtle Dermochelys coriacea. Brit. Herpetol. Soc. Bull. 62, 4-8.

Day, R., 2003. Mercury in loggerhead sea turtles, Caretta caretta: developing monitoring strategies, investigating factors affecting contamination, and assessing health impacts. Master's Thesis. University of Charleston, Charleston, SC, USA.

Debier, C., Pomeroy, P.P., Dupont, C., Joiris, C., Comblin, V., Le Boulenge, E., Larondelle, Y., Thome, J.P., 2003. Quantitative dynamics of PCB transfer from mother to pup during lactation in UK grey seals Halichoerus grypus. Mar. Ecol. Prog. Ser. 247, 237-248.

Debier, C., Chalon, C., Le Boeuf, B.J., de Tillesse, T., Larondelle, Y., Thome, J.P., 2006. Mobilization of PCBs from blubber to blood in northern elephant seals (Mirounga angustirostris) during the post-weaning fast. Aquat. Toxicol. 80, 149-157.

Doyle, T.K., Houghton, J.D.R., O'Suilleabhain, P.F., Hobson, V.J., Marnell, F., Davenport, J., Hays, G.C., 2007. Leatherback turtles satellite-tagged in European waters. Endang. Species Res. 3.

Fisk, A.T., de Wit, C.A., Wayland, M., Kuzyk, Z.Z., Burgess, N., Robert, R., Braune, B., Norstrom, R., Blum, S.P., Sandau, C., Lie, E., Larsen, H.J.S., Skaare, J.U., Muir, D.C.G., 2005. An assessment of the toxicological significance of anthropogenic contaminants in Canadian arctic wildlife. Sci. Total Environ. 351, 5793.

Fossette, S., Ferraroli, S., Tanaka, H., Ropert-Coudert, Y., Arai, N., Sato, K., Naito, Y., Le Maho, Y., Georges, J.Y., 2007. Dispersal and dive patterns in gravid leatherback turtles during the nesting season in French Guiana. Mar. Ecol. Prog. Ser. 338, 233-247.

Gibbons, J.W., Scott, D.E., Ryan, T.J., Buhlmann, K.A., Tuberville, T.D., Metts, B.S., Greene, J.L., Mills, T., Leiden, Y., Poppy, S., Winne, C.T., 2000. The global decline of reptiles, Deja Vu amphibians. Bioscience 50, 653-666.

Girondot, M., Fretey, J., 1996. Leatherback turtles, Dermochelys coriacea, nesting in French Guiana, 1978-1995. Chelonian Conserv. Biol. 2, 204-208.

Guirlet, E., Das, K., Girondot, M., 2008. Maternal transfer of trace elements in leatherback turtles (Dermochelys coriacea) of French Guiana. Aquat. Toxicol. 88, 267-276.

Hamann, M., Limpus, C.J., Whittier, J.M., 2002. Patterns of lipid storage and mobilisation in the female green sea turtle (Chelonia mydas). J. Comp. Physiol. B - Biochem. Syst. Environ. Physiol. 172, 485-493.

Hays, G.C., Houghton, J.D.R., Myers, A.E., 2004. Endangered species - Pan-Atlantic leatherback turtle movements. Nature 429, 522.

Houghton, J.D.R., Doyle, T.K., Wilson, M.W., Davenport, J., Hays, G.C., 2006. Jellyfish aggregations and leatherback turtle foraging patterns in a temperate coastal environment. Ecology 87, 1967-1972.

James, M.C., Myers, R.A., Ottensmeyer, C.A., 2005a. Behaviour of leatherback sea turtles, Dermochelys coriacea, during the migratory cycle. Proc. R. Soc. B - Biol. Sci. 272, 1547-1555

James, M.C., Ottensmeyer, C.A., Myers, R.A., 2005b. Identification of high-use habitat and threats to leatherback sea turtles in northern waters: new directions for conservation. Ecol. Lett. 8, 195-201.

Janak, K., Jensen, E., Becher, G., 1999. Determination of polychlorinated biphenyls in human blood by solid phase extraction including on-column lipid decomposition. J. Chromatogr. B 734, 219-227.

Keller, J.M., Kucklick, J.R., Andrew Stamper, M., Harms, C.A., McClellan-Green, P.D., 2004a. Associations between organochlorine contaminant concentrations and clinical health parameters in loggerhead sea turtles from North Carolina, USA Environ. Health Perspect. 112, 1074-1079.

Keller, J.M., Kucklick, J.R., Harms, C.A., McClellan-Green, P.D., 2004b. Organochlorine contaminants in sea turtles: correlations between whole blood and fat. Environ. Toxicol. Chem. 23, 726-738.

Keller, J.M., Kucklick, J.R., McClellan-Green, P.D., 2004c. Organochlorine contaminants in loggerhead sea turtle blood: extraction techniques and distribution among plasma and red blood cells. Arch. Environ. Contam. Toxicol. 46, 254-264. 
Kelly, J.F., 2000. Stable isotopes of carbon and nitrogen in the study of avian and mammalian trophic ecology. Can. J. Zool. - Rev. Can. Zool. 78, 1-27.

Lacher, T.E., Goldstein, M.I., 1997. Tropical ecotoxicology: status and needs. Environ. Toxicol. Chem. 16, 100-111.

Lydersen, C., Wolkers, H., Severinsen, T., Kleivane, L., Nordoy, E.S., Skaare, J.U., 2002 Blood is a poor substrate for monitoring pollution burdens in phocid seals. Sci. Total Environ. 292, 193-203.

McKenzie, C., Rogan, E., Reid, R.J., Wells, D.E., 1997. Concentrations and patterns of organic contaminants in Atlantic white-sided dolphins (Lagenorhynchus acutus) from Irish and Scottish coastal waters. Environ. Pollut. 98, 15-27.

McKenzie, C., Godley, B.J., Furness, R.W., Wells, D.E., 1999. Concentrations and patterns of organochlorine contaminants in marine turtles from mediterranean and Atlantic waters. Mar. Environ. Res. 47, 117-135.

Miao, X., Balazs, G.H., Murakawa, S.K.K., Li, Q.X., 2001. Congener-specific profile and toxicity assessment of PCBs in green turtles (Chelonia mydas) from the Hawaiian Islands. Sci. Total Environ. 281, 247-253.

Miller, J.D., 1997. Reproduction in sea turtles. In: Lutz, P.L., Musick, J.A. (Eds.), The Biology of Sea Turtles. CRC Press, pp. 51-82.

Pauwels, A., Wells, D.A., Covaci, A., Schepens, P.J.C., 1999. Improved sample preparation method for selected persistent organochlorine pollutants in human serum using solid-phase disk extraction with gas chromatography analysis. J. Chromatogr. B 723, 117-125.

Rauschenberger, R.H., Sepulveda, M.S., Wiebe, J.J., Ruessler, D.S., Wieser, C.M., Gross, T.S., 2002. Predicting contaminant body burdens from eggs and evidence of maternal transfer in Alligator mississippiensis. The Society for Environmental Toxicology and Chemistry 23rd Annual Meeting, Salt Lake City, UT.

Rauschenberger, R.H., Wiebe, J.J., Buckland, J.E., Smith, J.T., Sepulveda, M.S., Gross, T.S., 2004. Achieving environmentally relevant organochlorine pesticide concentrations in eggs through maternal exposure in Alligator mississippiensis. Mar. Environ. Res. 58, 851-856.

Rivalan, P., Prevot-Julliard, A.C., Choquet, R., Pradel, R., Jacquemin, B., Girondot, M., 2005. Trade-off between current reproductive effort and delay to next reproduction in the leatherback sea turtle. Oecologia 145, 564-574.

Russell, R.W., Gobas, F., Haffner, G.D., 1999. Maternal transfer and in ovo exposure of organochlorines in oviparous organisms: a model and field verification. Environ. Sci. Technol. 33, 416-420.
Snedaker, S.C., Araujo, R.J., Capin, A.A., Hearon, M.D., Ofengand, E.A., 1999 Organochlorine compounds in subtropical and tropical organisms: a metaanalysis. Toxicol. Ind. Health 15, 214-230.

Sunbdberg, S.E., Ellington, J.J., Evans, J.J., 2006. A simple and fast extraction method for organochlorine pesticides and polychlorinated biphenyls in small volumes of avian serum. J. Chromatogr. B 831, 99-104.

Takai, N., Onaka, S., Ikeda, Y., Yatsu, A., Kidokoro, H., Sakamoto, W., 2000 Geographical variations in carbon and nitrogen stable isotope ratios in squid. J. Mar. Biol. Assoc. UK 80, 675-684.

Van den Steen, E., Jaspers, V.L.B., Covaci, A., Neeis, H., Eens, M., Pinxten, R., 2009 Maternal transfer of organochlorines and brominated flame retardants in blue tits (Cyanistes caeruleus). Environ. Int. 35, 69-75.

Verreault, J., Villa, R.A., Gabrielsen, G.W., Skaare, J.U., Letcher, R.J., 2006. Maternal transfer of organohalogen contaminants and metabolites to eggs of Arcticbreeding glaucous gulls. Environ. Pollut. 144, 1053-1060.

Wallace, B.P., Williams, C.L., Paladino, F.V., Morreale, S.J., Lindstrom, R.T., Spotila J.R., 2005. Bioenergetics and diving activity of internesting leatherback turtles Dermochelys coriacea at Parque Nacional Marino las Baulas, Costa Rica. J. Exp. Biol. 208, 3873-3884.

Wallace, B.P., Sotherland, P.R., Tomillo, P.S., Bouchard, S.S., Reina, R.D., Spotila, J.R. Paladino, F.V., 2006. Egg components, egg size, and hatchling size in leatherback turtles. Comp. Biochem. Physiol. A - Mol. Integr. Physiol. 145, 524-532.

Ward, J.R., Lafferty, K.D., 2004. The elusive baseline of marine disease: are diseases in ocean ecosystems increasing? Plos Biol. 2, 542-547.

Willingham, E., 2001. Embryonic exposure to low-dose pesticides: effects on growth rate in the hatchling red-eared slider turtle. J. Toxicol. Environ. Health Part A 64, 257-272.

Woodward, A.R., Percival, H.F., Jennings, M.L., Moore, C.T., 1993. Low clutch viability of american alligators on Lake Apopka. Florida Scientist 56, 52-63.

Wu, T.H., Rainwater, T.R., Platt, S.G., McMurry, S.T., Anderson, T.A., 2000 Organochlorine contaminants in Morelet's crocodile (Crocodylus moreletii) eggs from Belize. Chemosphere 40, 671-678. 